\title{
Recollections of V. S. Varadarajan
}

\section{Don Blasius, Trond Digernes, Rita Fioresi, Ramesh Gangolli, Michael Rapoport, and S. R. S. Varadhan}

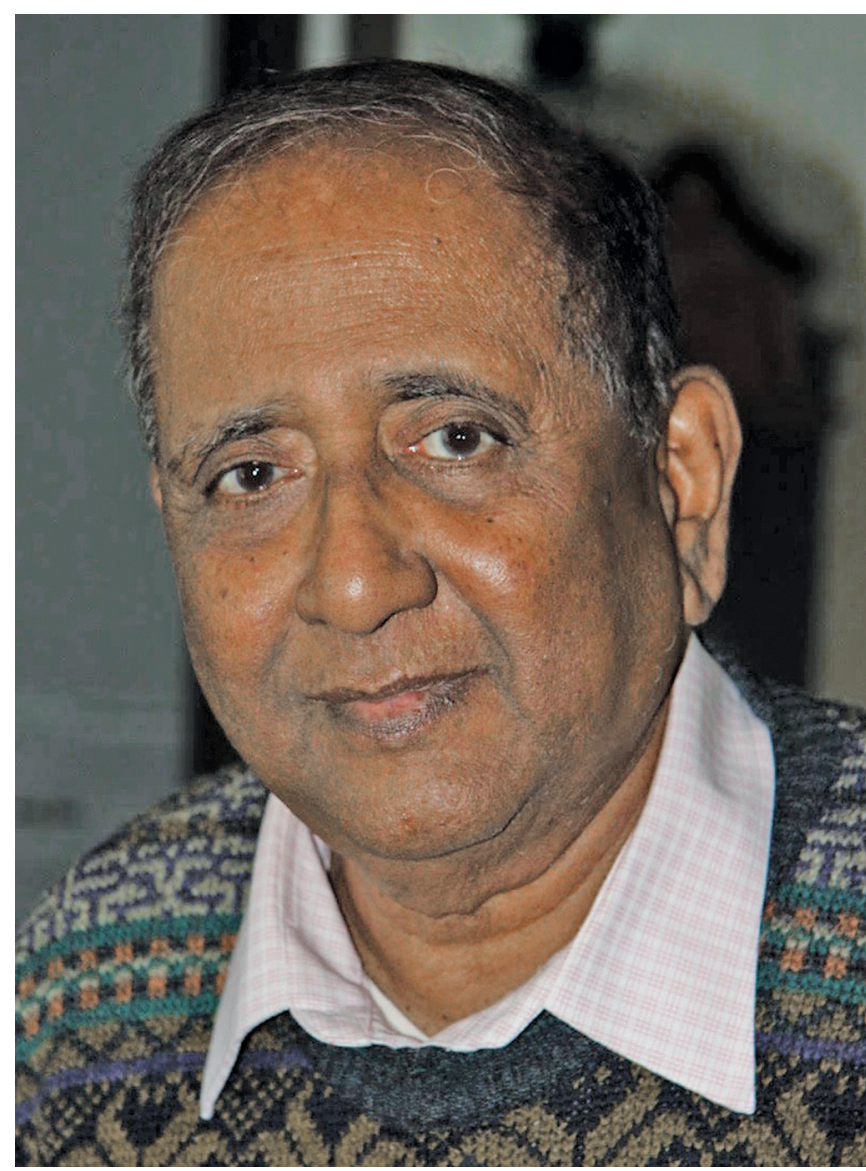

Figure 1. V. S. Varadarajan, UCLA, 2008.

For permission to reprint this article, please contact:

reprint-permission@ams.org.

DOI: https://doi.org/10.1090/noti2154
Known to friends, students, and colleagues just as Raja, Veeravalli Seshadri Varadarajan (born May 18, 1937) was a mathematician of Indian origin who made foundational contributions to multiple fields, including probability, the representation theory of Lie groups, quantum mechanics, and differential equations. Varadarajan received his $\mathrm{PhD}$ from the Indian Statistical Institute in 1960. In 1965, after several visits to the US, he became an associate professor at UCLA. After a long and illustrious career, he retired from UCLA in 2014, remaining active in research, despite declining health, as a Distinguished Research Professor until his death on April 25, 2019.

Varadarajan was an ICM speaker in 1974. His international recognitions include an honorary doctorate from the University of Genoa and the Lars Onsager Medal from the Norwegian University of Science and Technology. He wrote numerous well-known texts and monographs, some published by the AMS, which also published a volume of his selected works in 1999.

\section{S. R. S. Varadhan}

I first heard of Raja when I was in the second year of my three-year degree program in statistics at the Presidency College in Chennai, or Madras as it was then called. He had graduated in the summer of 1956 just before I joined the program. The faculty remembered him as a student with extraordinary talent, and some of his work was shown to us as models of mathematical writing. He authored several books during his career, and they all reflect this talent.

S. R. S. Varadhan is a professor of mathematics at New York University. His email address is varadhan@cims. nyu. edu. 
After graduation he joined the Indian Statistical Institute (ISI) in Calcutta (or Kolkata as it is called now). Started by Professor P. C. Mahalanobis, it was primarily an institution for research and training in statistics. The eminent statistician Dr. C. R. Rao was the head of its research and training school. Raja joined as a research scholar, and his interest was in mathematics, although his bachelor's degree was in statistics. He interacted with Professor Vaidyanathaswami, who was at ISI after retirement from the University of Madras. That got Raja familiar with point set topology.

Limit theorems play an important role in probability theory and statistics. Raja's thesis work was on measures on topological spaces, particularly on their weak convergence. This work has influenced my work as well as the work of Ranga Rao and Parthasarathy before me.

There was a breakthrough made by M. Donsker, who proved a limit theorem for probability distributions in an infinite-dimensional setting where Fourier transforms are not very useful. He showed the convergence of random walks to Brownian motion. The random walk, although defined for discrete times, can be linearly interpolated to provide a random curve $S_{n}(t)$ with $S_{n}(k)=X_{1}+\cdots+X_{k}$. So long as $X_{i}$ are independent identically distributed random variables with $E\left[X_{i}\right]=0$ and $E\left[X_{i}^{2}\right]=1$, the distribution $P_{n}$ of $\frac{1}{\sqrt{n}} S_{n}(n t)$, as a random function of $t$ on the space $\Omega$ of continuous functions $\omega$ on $[0,1]$, converges to the Wiener measure $P$ of Brownian motion $x(t)$. The convergence is in the sense of weak convergence of probability distributions; i.e.,

$$
\lim _{n \rightarrow \infty} \int F(\omega) d P_{n}=\int F(\omega) d P
$$

for all bounded functions $F$ on $\Omega$ that are continuous in the uniform topology on $\Omega$.

This was taken up by the Russian School by students of Kolmogorov. In particular, Prohorov and Skorohod developed the theory in the context of weak convergence of probability distributions on complete separable metric spaces. Raja more or less independently developed it in the context of general topological spaces.

In a separable metric space the weak distance between two probability distributions $\alpha$ and $\beta$ as defined by Prohorov is a variation of what Paul Levy defined in the case of the real line

$$
d(\alpha, \beta)=\inf \left\{\epsilon: \alpha(G) \leq \beta\left(G_{\epsilon}\right)+\epsilon\right\}
$$

for all open sets $G$ where $G_{\epsilon}=\bigcup_{x \in G} B(x, \epsilon)$. In case the space is compact, $C(X)$ is separable, and if $\left\{f_{n}\right\}$ is a countable dense set, then

$$
d(\alpha, \beta)=\sum_{n} \frac{1}{2^{n}} \frac{1}{1+|| f_{n} \|}\left|\int f_{n} d \alpha-\int f_{n} d \beta\right|
$$

is also a metric. If the space is not compact, there is always a metric under which the space of uniformly continuous functions is separable, and a dense subset of that will work equally well. Varadarajan's thesis is full of such ideas from functional analysis.

Another gem found in Ranga Rao's thesis concerns the question of whether a sequence $X_{i}$ of independent identically distributed random variables with values in a Banach space, and which satisfies $E[\|X\|]<\infty$, obeys a law of large numbers in the Banach norm. In other words, is it true that

$$
\lim _{n \rightarrow \infty}\left\|\frac{1}{n}\left(X_{1}+\cdots+X_{n}\right)-E[X]\right\|=0
$$

almost surely? The French school had worked on this problem with partial success, proving the result under additional stringent conditions. Continuing in the spirit of Raja's work, Ranga Rao provided the following elegant proof valid in complete generality. First, if $\left\{X_{i}\right\}$ are independent and identically distributed with distribution $\mu$, the empirical distribution

$$
L_{n}(d x)=\frac{1}{n} \sum \delta_{X_{i}} \rightarrow \mu
$$

almost surely. This is done by integrating against a countable set of continuous functions. The next question is when does weak convergence of $\mu_{n}$ to $\mu$ imply

$$
\sup _{f \in A}\left|\int f d \mu_{n}-\int f d \mu\right| \rightarrow 0 ?
$$

It is enough if the functions in $\mathcal{A}$ are equicontinuous and are dominated by a continuous function $g$ satisfying

$$
\left|\int g d \mu_{n}-\int g d \mu\right| \rightarrow 0 \text {. }
$$

This uses the facts that a weakly converging sequence of probability distributions is essentially supported on a common compact set and the linear functionals $\Lambda(x)$ with $\|\Lambda\| \leq 1$ are equicontinuous. With $g(x)=\|x\|$, the law of large numbers holds.

All of this took a relatively short time. After finishing this thesis Raja started his study on foundations of quantum mechanics and developed an interest in mathematical physics and representation theory of Lie groups.

It was at this time in August of 1959 that I joined ISI as a research scholar and really met Raja. He was preparing to go to Princeton to study representation theory and interact with Professor Harish-Chandra at the Institute for Advanced Study. We overlapped for three months. He gave a course on point set topology which I attended. We did not have much interaction during this period. At that time I thought I was going to work on applied statistics.

Ranga Rao and Parthasarathy, who were there, had interacted with Raja for nearly three years. They were more interested in the mathematical aspects of probability and 


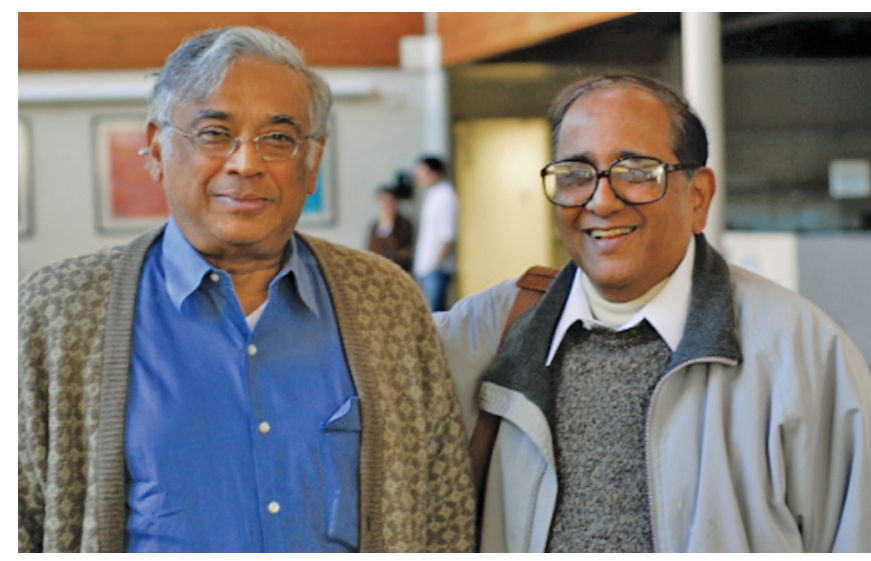

Figure 2. Raja with his life-long friend S. R. S. Varadhan, UCLA, 2010.

sometime after Raja left for Princeton attracted me to their group and we started working together.

By 1962 Ranga Rao had left for the USA and Parthasarathy to Russia. Raja had returned and joined ISI, and the two of us worked closely for a year. I had submitted my thesis and was planning to go to the US in the fall of 1963. We studied Harish-Chandra's work on representation theory and began to understand parts of it. It was a lot of fun working with him, and I developed a bond with Raja and his wife Veda. He was the one that suggested I go to the Courant Institute and arranged a postdoc position for me.

After Raja moved to UCLA in 1965 we remained in close touch, and I cherish his friendship.

\section{Michael Rapoport}

I first met Raja in the seventies, when he was a visiting professor at IHES, during the time in which I was a student there. I have to admit that I took no notice of him at the time. Fortunately, it was different for Raja and his wife Veda, who both, for some reason, took an immediate liking to me from a distance and invited me for dinner to their apartment at the Résidence de L'Ormaille: as they explained to me, "to see how Rapoport ticks." Even now, more than forty years later, this seems quite extraordinary to me: I was a young student, whereas Raja was already then a full professor at a prestigious university. With hindsight, I recognize a characteristic of Raja: the enormous respect he had for others. Raja and I never collaborated and were not even mathematically close, but we discussed mathematics in many ways. Raja was interested in an extraordinary range of mathematics (for instance, I remember him asking me to translate for him in his house the letter of

Michael Rapoport is a professor of mathematics at the University of Bonn. His email address is rapoport@math.uni-bonn. de.
Kronecker to Dedekind in which he talks of his "liebster Jugendtraum," after which he said to me that thinking about this should keep him busy for the next year). I think he most enjoyed it when cross-connections occurred. In any case, mathematics was for him a cultural endeavor, which also explains his keen interest in the history of mathematics.

One of the remarkable things about Raja was his ability to adjust his way of thinking to many subjects. This is how I explain to myself the fact that even though his upbringing did not include classical Western music, he had a deep understanding of it, and we could both share our unbounded admiration of Mozart. Another remarkable thing about Raja was his boyish humor with which he could on the spur of the moment deflate some pompous presentation. This surely was a prime reason why his company was so enjoyable. I end with an anecdote which combines both these characteristics. In 1977 Raja and Veda invited me to visit them in their house after the Corvallis conference. They wanted to give me a present. Since at the time it was impossible to get an Indian present, they decided to take me to a Japanese store: they had just been to Japan the year before and were quite enthusiastic about Japanese culture. While Veda was wandering through the store, Raja had an extensive conversation with the store owner, a very old, stooped Japanese gentleman without teeth. When we left the store, I expressed to Raja my admiration for his ability to carry on a conversation in Japanese, after being exposed to the language for only a short period. Raja's response was, "What Japanese? That was English!" And he added, "You see, having grown up in India, I can understand and speak English in any way required!" The yukata Raja and Veda gave me then is still in my use. It reminds me of my encounter with one of the most remarkable human beings in my life.

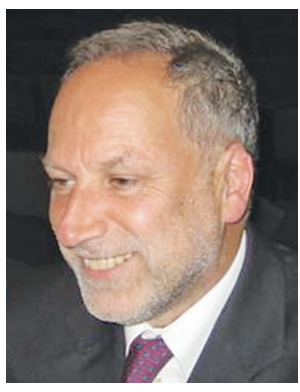

Michael Rapoport 


\section{Ramesh Gangolli}

I first met Varadarajan when I spent six months at the Indian Statistical Institute (ISI) in 1958, as a graduate student before going to MIT for my doctoral studies. I consider this period to be the most fruitful in shaping my view of mathematics and its elegance. At that time Varadarajan (already called Raja by all his friends) was clearly the leader of an exceptional group of graduate students at ISI, sallying forth into areas in mathematics which were then emerging, and getting original results essentially on their own without significant guidance from anyone. K. R. Parthasarathy and Ranga Rao were two other prominent members of the group. Although Raja was formally registered as a PhD student under the guidance of the brilliant statistician C. R. Rao, who was then the head of the Research Training School of the ISI, his tastes had already taken him towards the advances in probability theory that had been made in the early 1950s by mathematicians of the Russian School, notably Kolmogorov and Prokhorov, and he had embarked on a completely independent path. Within a few days after my arrival, I realized that Raja was not your ordinary guy. He had learned, completely on his own, what were then emerging as new areas in the world of mathematics, and initiated the rest of the group into this new world. As a newcomer, I was not immediately accepted by the group, but was not purposefully excluded. The small initial reserve towards me was a natural facet of group dynamics, and it soon disappeared, and I began to see through my interaction with Raja how a really fine mind operates. I spent hours in his company, and learned a great deal about how one should think about mathematics. Immediately after this period, our paths diverged for a few years, although we kept in touch sporadically. Raja's path had become intensely curious mathematically. In his stay in the United States during 1960-62, he had encountered some of the great minds of mathematics: Mackey, Lax, Friedrichs, and Harish-Chandra, among others.

These encounters defined his career in mathematics. After his return to ISI in 1962, he resumed his collaboration with his erstwhile group, and this time led them into studying some problems of representation theory of semisimple Lie algebras, and also leading some study seminars on quantum physics. One of his early landmark papers in representation theory was written in collaboration with Parthasarathy and Ranga Rao in the two years after his return, and attracted immediate attention of experts such as Harish-Chandra and Kostant. Soon afterwards, Raja accepted a position at UCLA, where he spent the rest of

Ramesh Gangolli is a professor of mathematics at the University of Washington. His email address is gango11ir@comcast.net. his life. In the meantime, I had followed my own path. After finishing my PhD in 1961 at MIT, I taught there as an instructor for a year and then came to the University of Washington at Seattle in 1962. I was finding my feet in the world of mathematics, and soon found myself being attracted to the area of analysis on symmetric spaces, which was intimately connected with Lie groups and representation theory, and which was now also one of Raja's principal interests. Thus, after Raja came to UCLA, we renewed our contact, and began to be in close touch. Both of us being on the West Coast enabled us to see each other more often. Raja had married his college sweetheart Veda after his return to India in 1962, and my wife Shanta and I became close to Raja and Veda over the succeeding years, forging bonds of deep affection that have never weakened. We collaborated on two book-sized volumes in these years, the second one completed just last year. Raja and I shared many hours laughing and chatting. He had wide interests. For some years he took up the study of clarinet, and enjoyed trying to play some snatches of Mozart's clarinet pieces, especially his Clarinet Concerto K622. Shakespeare, the Mahabharata, Mozart, Bach, Wodehouse, Tin Tin, and the fortunes of the Los Angeles Lakers in the basketball championships were his unfailing passions. I shared all of them except the last one, but could not help but enjoy the total enthusiasm with which Raja would cheer his team while watching their games on TV. They were always referred to as the "beloved Lakers," while the epithet "hated" was used for any team that had the gumption to vie against them.

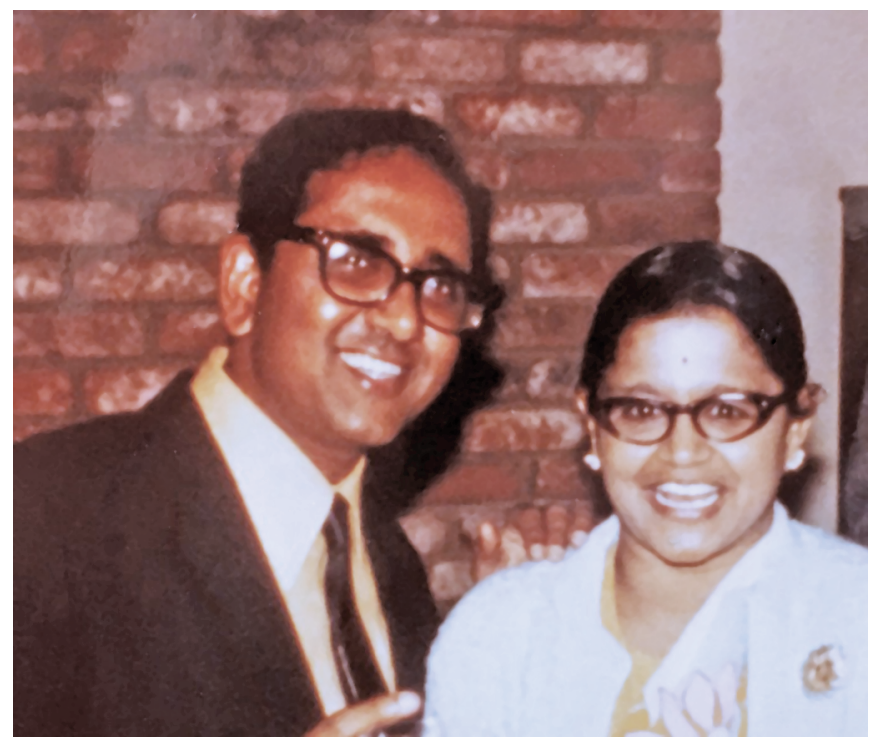

Figure 3. Raja and Veda, circa 1968. 
Most mathematicians are content to spend their research career on one or two areas of mathematics. Raja contributed to a host of them, at a high level. His work ranges over probability theory, measures on topological spaces, representation theory of semisimple Lie algebras, analysis on semisimple Lie groups and their quotients, algebraic geometry of differential equations, mathematical foundations of quantum theory, and supersymmetry and related questions of mathematical physics. In addition he has written beautifully crafted historical articles, scores of lecture notes, reviews, all done in an impeccably clear and elegant, almost poetic, style. Raja had a unique gift for communicating with his doctoral students and the younger colleagues who came under his spell. Almost all of them became his friends. On the one hand, he inspired them to excel, by the force of his example and his expectations; on the other hand, he showered them with unreserved friendship. This was handsomely reciprocated by those who benefitted from it. I could recount many anecdotes about this, but one sticks out in my mind. Raja had developed a continuing relationship with physicists and mathematicians at the University of Genoa, and made many visits there. On the occasion of his seventieth birthday, there was a conference at UCLA which was attended by many of his colleagues, students, etc. There was also a large contingent from Genoa. Speeches were made, dinners were eaten, wine drunk, but the most touching moment was when, as Raja and Veda rose to go home after the banquet at the conclusion of the conference, the Genoa contingent, by placing its members on opposite sides of their path, formed a canopy of outstretched arms, a "guardia d'onore," under which they had to pass, amidst cheers of good wishes.

Collaborating with Raja, learning from him, and enjoying his friendship and humor have been great gifts for me. For his own part, Raja was a lifelong admirer of the work of Harish-Chandra. In turn Harish-Chandra also recognized Raja's powers, and they were good friends. Harish died in 1983, alas too early in his life. He left a large body of manuscripts dealing with many topics. For many years Raja had wanted to see what they contained, and whether the contents could be organized into a coherent account of the topics they addressed. A couple of years after his seventieth birthday, he and I decided to collaborate on this project, encouraged by Robert Langlands, who had attended the conference. We worked in fits and starts, but never abandoned the project, and we were able to salvage a considerable amount of valuable material. That material was published in July of 2018 as the fifth (posthumous) volume of Harish-Chandra's Collected Works by Springer Verlag, (the same publisher that published the first four volumes) with the two of us cited as editors. Raja was very gratified to see the completion of this project, and I am happy to have contributed to his joy. The last three years were very trying for Raja and Veda. Both have had health issues of different kinds. Raja was harried by diabetes and accompanying afflictions that affected his heart and kidneys. But fortunately, he was able to function, and he kept on working on mathematics till the end, which came peacefully, on the 25th of April, mercifully without the suffering and indignities which are often our lot. As I know from my collaboration with him on the HarishChandra volume, he lost none of his incisiveness and clarity till the end. His passing is a great personal loss for me. He was a friend and an inspiration. But age brings with it an ability to face the bitterness of the loss of friends by taking comfort in the gentleness of their passing, if they are so favored.

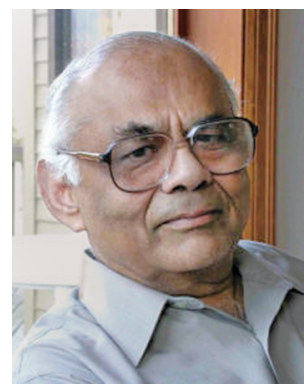

Ramesh Gangolli

\section{Trond Digernes}

I had met Raja already during my first quarter at UCLA (fall 1971), but we didn't start discussing mathematics until some twenty years later. It started in a small way in the winter of 1990 when I came to UCLA from Australia and gave a talk on some material I had discussed with colleagues at the Australian National University in Canberra. Raja took an interest in the topic (elliptic operators on Lie groups), and we met for discussions a few times. However, we didn't pursue that subject. When Raja visited Trondheim the year after, we had both gotten interested in finite models for quantum mechanics, and the question of whether these converged to the full model. I had read an article by W. Arveson on the subject, whereas Raja was inspired by a couple of articles by J. Schwinger from 1960 . Schwinger claimed-but didn't rigorously prove-that his finite models converged to the continuous model in a certain strong sense. Raja felt we should try to prove this. I did some numerical computations for the finite harmonic oscillator, and the results made it clear that there was

Trond Digernes is emeritus professor of mathematics at the Norwegian University of Science and Technology. His email address is trond.digernes@ntnu no. 
something to prove here: the eigenvalues and eigenfunctions of the finite model were remarkably close to those of the continuous model. The proof, however, ran into some technical challenges, so Raja invited his good friend S. R. S. Varadhan to join the project. With Varadhan onboard the proof was completed, and in two ways: by standard functional analytic methods and by stochastic methods that improve the results achieved with the functional analytic methods.

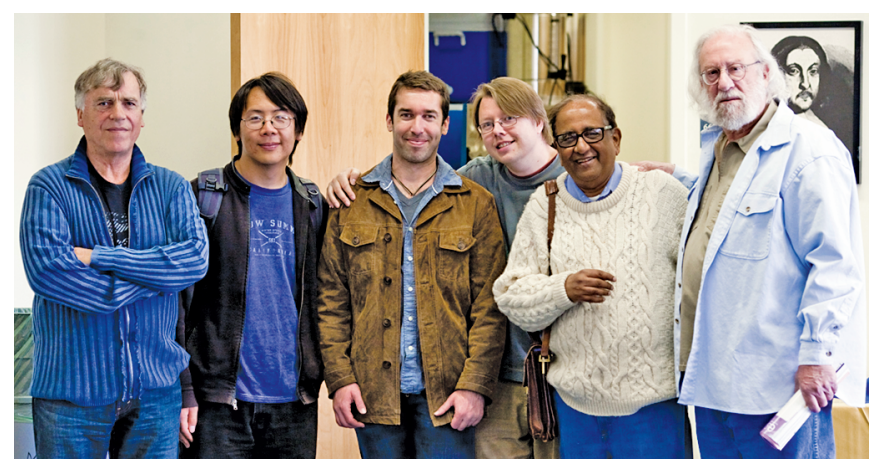

Figure 4. From left: Trond Digernes; Raja's students Stephen Kwok, David Weisbart, Jukka Virtanen; Raja; UCLA, colleague Nate Grossman. UCLA, 2010.

Raja's motivation for studying finite approximations can be seen in the following quote from a talk he gave in Dubna, Russia, in 1995: "In their works on the foundations of quantum theory, Schwinger and Weyl considered usual quantum mechanics as the limiting case of quantum mechanics over finite fields and groups. These limiting procedures suggest that there are interesting generalizations when the real field is replaced by the p-adic field." In this spirit Raja and I, together with Espen Husstad, a student of mine, published an article on finite approximations of Weyl systems. The setting was more general than in the above-mentioned article, but the mode of convergence was weaker.

It was en route to the Dubna conference in 1995, during a stopover in Trondheim, that Raja first talked to me about non-Archimedean physics, a subject which had been introduced just a few years earlier (in 1987) by the Russian mathematical physicist I. Volovich. Part of the philosophy here is that phenomena below the Planck scale are best described by a non-Archimedean geometry, as ordinary Archimedean measurements break down in this regime. The $p$-adic numbers lend themselves to this theory, since they come equipped with a non-Archimedean absolute value, and since they are the completion of the rational numbers with respect to this absolute value (the rational numbers must be at the base of any physical theory, since the outcome of any measurement is a rational number).
Since there is no preferred prime in nature, one eventually has to consider all of them in one go, and this leads to the adelic theories. Raja made several important contributions to non-Archimedean physics (sometimes also referred to as arithmetical physics), both of an analytical and a philosophical nature. He also devoted a whole chapter of his book Reflections on Quanta, Symmetries, and Supersymmetries to this theory.

Raja's third visit to Trondheim was in 1998, when he was awarded the Onsager Professorship and the Onsager Medal. The first Onsager Professorship was awarded in 1993. It is named in honor of Norwegian chemist and physicist Lars Onsager, who was awarded the Nobel Prize in Chemistry in 1968 for his work done in 1931 on irreversible thermodynamics.

My journey with Raja was a long and extremely interesting one. His keen understanding of both physics and mathematics always made it a rewarding experience to converse with him. In addition to his intellectual brilliance he also had a personality marked by hospitality and generosity. He is dearly missed and cannot be replaced.

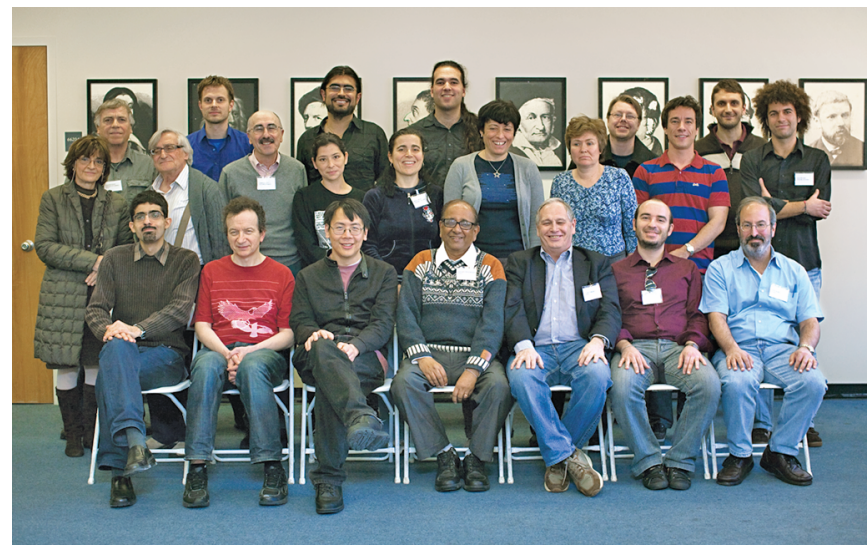

Figure 5. 2010 Birthday Conference, UCLA.

Back Row: T. Digernes, ?, ?, J. Huerta, J. Virtanen, C. Carmeli; Middle Row: Ms. Cassinelli, A. Schwarz, G. Cassinelli, D. Cervantes, R. Fioresi, M. A. Lledo, V. Serganova, D. W. Taylor, ?; Front Row: H. Salmasian, I. Musson, S. D. Kwok, Raja, S. Ferrara, A. Marrani, J. Rabin.

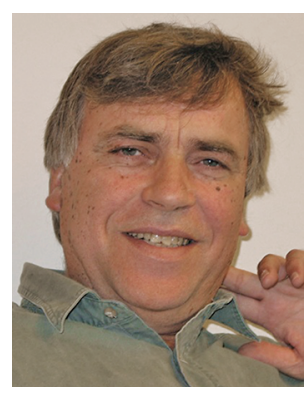

Trond Digernes 


\section{Rita Fioresi}

Professor V. S. Varadarajan was a terrific lecturer: his clarity of exposition made his lectures memorable for all the students in his classes, no matter at which level. He would often alternate theorems and proofs with remarks on the history and significance of the mathematics he was discussing, how ideas developed, how concepts came along. I recall a first-year graduate class where he lectured to us on the Langlands program. It was very inspiring, even more so when we found out he had a personal connection with Robert Langlands.

But he would also have witty remarks and interludes that made his classes very enjoyable. In the fall of 1992, he had a major heart attack and was hospitalized during finals week. At that time I was sitting in his graduate algebra class, and we sent him a very warm "get well soon" letter which we wrote during the final. When he came back in winter quarter, he started his lecture by saying, "In my previous incarnation...," very amusing.

Later on he told us that right before his operation of a quintuple bypass a priest came to give him the last rites according to the Catholic rituals. When the priest realized they were not sharing the same faith and was about to leave, Raja said, "Please stay, Father. One does not know who I will meet on the other side!"

While I was doing my $\mathrm{PhD}$ under his supervision, he became interested in the theory of quantum groups. On this topic, Raja ran a weekly participating seminar, attended by graduate students and faculty alike. He wrote a wonderful account on the theory of quantum groups, based on his lectures, that later was published as lecture notes. He focussed on the relation between quantum groups and the theory of quantum mechanics. In particular, he viewed quantum groups as an attempt to mathematically justify the irreconcilable difference between quantum mechanics and the deterministic approach of classical mechanics. Starting from the famous Heisenberg relation, formulated through the Lie bracket of the operators associated with the position and momentum of a particle $[q, p]=i \hbar$, Raja worked through Weyl quantization, to give a sound motivation for the introduction of the concept of quantum group, which he showed arises quite naturally in this framework. The Moyal-Weyl quantization, which was somehow a prelude to the theory of quantum groups, responds to the need to give a mathematically sound vest to this theory.

In general, most mathematicians working within this framework tend to overlook its fundamental physical

Rita Fioresi is an associate professor of mathematics at the University of Bologna. Her email address is rita.fioresi@unibo.it.

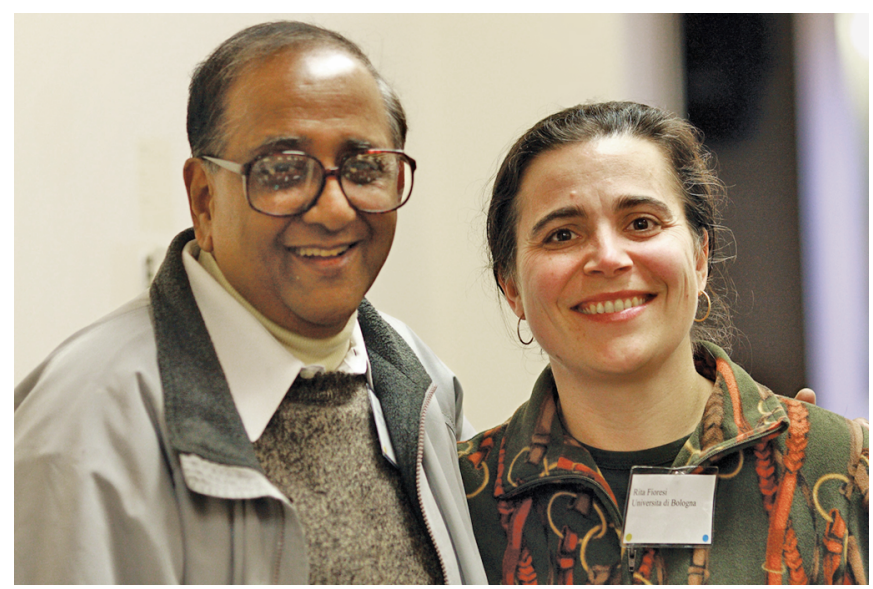

Figure 6. Rita Fioresi with Raja, UCLA, 2010.

significance and concentrate mainly on the mathematical properties of these objects. Raja was not at all like this: he wanted to give to any statement made by physicists a sound mathematical ground. For this reason he was revered by all of his physics friends. He collaborated with a group of physicists in Genoa on the theory of quantum groups and more generally on representation theory and its application to theoretical physics. Enrico Beltrametti, Gianni Cassinelli, Claudio Carmeli, and Piero Truini, to name just a few physicists in Genoa that had the pleasure to collaborate with Raja, have the utmost respect for his contribution to this field. His book Geometry of Quantum Theory is indeed one of the most authoritative references and mandatory reading for anyone who wants to take up the study of quantum mechanics with the necessary mathematical rigor.

Around the year 2000, Raja became interested in supersymmetry (SUSY), so he organized a joint weekly learning seminar with Sergio Ferrara and me. At that time I was expecting my first child Elia. Raja was convinced that Elia would be a natural mathematician, having attended his seminars before birth! His interest in SUSY took him to Naples, where his good friend Beppe Marmo organized his stay. From these lectures originated his AMS book Supersymmetry for Mathematicians: An Introduction, which immediately became the no. 1 bestseller of the AMS. Supersymmetry stems from the need to treat on equal grounds the two fundamental types of elementary particles, namely, boson and fermions, which obey the Bose-Einstein and Fermi-Dirac statistics, respectively. Physics tells us that we must allow transformations between these two types and consequently it is necessary to treat even (that is, commuting) and odd (that is, anticommuting) coordinates on equal grounds. Though no experimental evidence has confirmed the theory, the study of supersymmetry and supermanifolds has become a subject on its own in mathematics. In 
the last part of his life, Raja would listen over and over to Pierre Deligne's online lectures on SUSY curves, delivered in 2015 at a conference at the Simons Center, which he attended together with his students Stephen Kwok, David Taylor, and me. We would sit together through the lectures, and have our meals always together; somebody at the conference told us we seemed like a family, but actually this is the way we felt.

Raja was a Buddhist; he kept a poster of the Buddha in his office and a beautiful statue in his wonderful garden in Pacific Palisades. He was, however, not at all bounded by this faith only. He would often visit Catholic churches and enjoy the silence and meditation there. During his visits in Turin, working with the physicists Riccardo D'Auria and Marian Lledó, he once stopped at a Catholic church to light three candles: one to Jesus, one to Saint Mary, and one to Archangel Saint Michael, for three personal thoughts he had while meditating in there. During his Turin visit, he wrote a wonderful paper, joint with D'Auria, Ferrara, and Lledó, on spinor algebras, a construction that lies at the heart of spin groups, their representation, and the famous principle of triality originally introduced by Cartan.

He also was an avid fan of Mozart. Having listened to the famous clarinet concerto, he went ahead and first bought a clarinet and then started regular music tutoring at his house. When buying Mozart music scores at a local shop, a naive clerk asked him, "Are you Mr. Mozart?" to which he promptly replied, "I wish!"

He was extraordinarily generous in mathematics. He would talk with us, students and collaborators, for countless hours, simply enjoying the sharing of mathematical thoughts. He would have regular gatherings at his house, where his wife Veda would cook delicious Indian food for us, and then we would be together talking about mathematics and enjoying the beauty of his residence and the excellent cooking of Veda. There are no better times in our memory. He and Veda would host Thanksgiving dinners for all the students and friends, as both of them would consider students as family. Veda used to call my children "Raja's grandstudents," which we all found at the same time amusing and affectionate.

In the last part of his life, he was very weak and yet he would host friends and talk about mathematics at his house. He became fascinated with the adelic hypothesis to describe the physics of the microscopic world. He and his many collaborators had many ideas and plans to develop his wonderful intuitions. He is loved by many and will be missed.

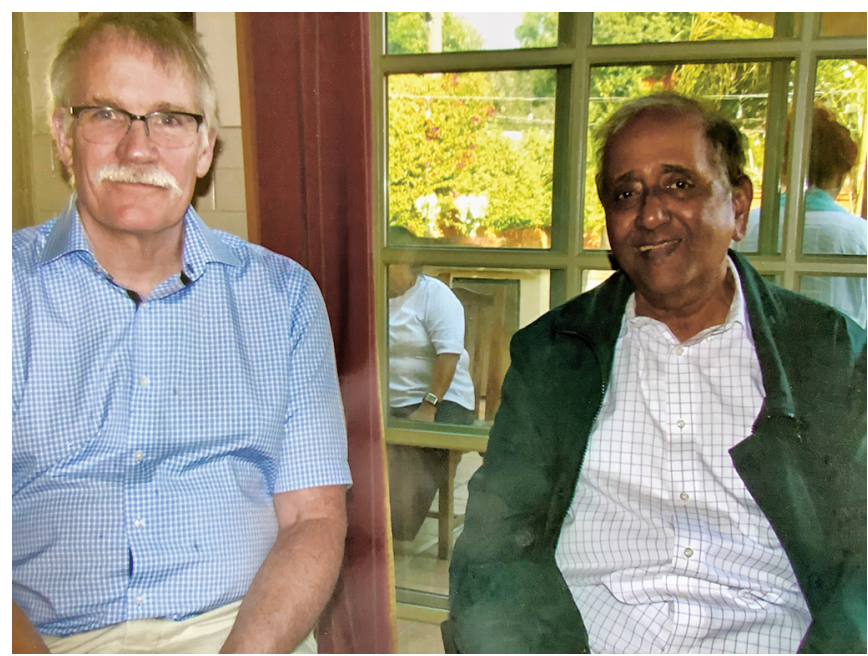

Figure 7. Don Blasius with Raja, UCLA, 2015.

\section{Don Blasius}

I met V. S. Varadarajan in the late 1980s while visiting UCLA. We spoke about his long collaboration with UCLA colleague and friend Don Babbitt on differential equations with irregular singular points. He explained their algebrogeometric method, based on suggestions of Deligne, for studying local moduli, as well as how it was motivated by problems arising in Harish-Chandra's work. The conversation transformed my view of the intellectual companionship awaiting me at UCLA, whose faculty I decided to join in that period.

Despite this promising beginning, we did not interact a lot during my first years at UCLA. I was involved in my projects, students, and collaborations, as was he with his. Eventually, a natural context for us to get to know each other arose. The department had chosen Raja to be the organizer of UCLA Math's new Distinguished Lecture Series. With his intelligence, breadth, and grace, he counted transformative senior mathematicians among his friends and acquaintances. So Raja was brilliantly successful in recruiting speakers of the highest renown: in those first years, speakers, who gave intensive courses of one month, included Atiyah, Deligne, Langlands, Serre, Singer, and Yau. Sometime in the second or third year of the program, Raja asked me to work on it with him. We became good friends as we evolved the program in the period 2000-2008. At the end of this service, the Mathematics Department gave Raja an award, which he valued highly, for this service to UCLA. The program continues with success today.

Don Blasius is Distinguished Professor of Mathematics at UCLA. His email address is blasius@math.ucla.edu. 
Once friendship started, Raja and his wife Veda welcomed Peter (my life partner) and me into their home. Since then, we have regularly joined them for Thanksgiving dinner and their July barbecue. The latter was held in their beautiful garden with its tranquil pine trees. The company at these events (and their annual New Year's Day party) was a mixture of academics, not all from UCLA, and others from their lives. These events were reliable social fixtures for forty years.

Conversation with Raja was a unique delight. As all his friends witness, he had a remarkable memory of the vast range of his experiences. He also had a strong interest in the lives of mathematicians and he knew many stories and quotes. One of his favorites was from HarishChandra, who told Raja, when discussing the idea of working in physics, that he felt it likely that if he tried he would just drive his Porsche off the road into a ditch. Of course, Harish-Chandra had no Porsche; he was speaking of his mathematical talent. Raja repeated variants of this remark, with himself and others as subject, with relish but also seriousness. Mercedes was his preferred auto brand for the story, and of course he dropped the reference to physics so it became a counsel against distraction by trivial things or bad problems.

For two decades he and Veda have been a prime source of recommendations for mysteries, especially classic British crime fiction, including those on television. Once, to start the conversation, I mentioned that I had seen an episode of the British series Midsomer Murders the night before. He perfectly recalled the plot of the episode, which he had seen years before, and even corrected me on a point.

Raja had his own guides and heros, both living and from the past. He had three about whom he spoke regularly and whose direct influence was enormous: Mackey, Harish-Chandra, and Deligne, and he has written about these influences in his book Reminiscences. From the recent past, Hermann Weyl was another luminary, and from an earlier era, he admired Euler and wrote a book on his work for contemporary mathematicians.

About thesis students, Raja had a distinct change of philosophy in the late 1980s. Until that point he had asked prospective students to read his famous 1974 text Lie Groups, Lie Algebras and Their Representations as a first step. He remarked wryly that he rarely saw them again, and indeed only three of his seventeen students finished before this change. So he decided he wanted more students and began coaching students intensely from the start. With this philosophy, he became a highly effective advisor and he found great personal reward in his advising and the friendships and collaborations that evolved.

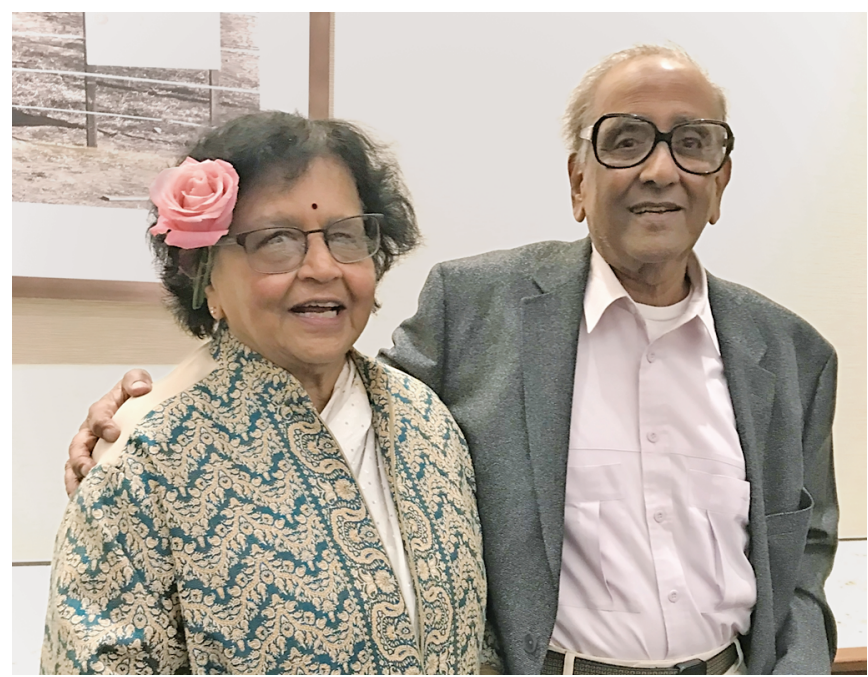

Figure 8. Raja and Veda, March 2019, on occasion of their \$1 million gift to found the Ramanujan Visiting Professorship at UCLA.

As surveyed in his Reminiscences, Raja's interests evolved greatly over his career, although he always kept in the orbits of representation theory and quantum mechanics. He kept working unto the last. He was very happy when he completed just several years ago a longstanding and exhausting project with Ramesh Gangolli to edit and publish, as a fifth volume of the Collected Papers, notes left by Harish-Chandra on the representation theory of $p$-adic groups. This appeared in 2018. He also left a research article, joint with his former student David Taylor, in a late stage of revision at the Pacific Journal of Mathematics. It concerns geometrically defined measures on schemes, especially homogeneous schemes, over local fields. It incorporates his three favorite areas of mathematics-Lie theory, number theory, and algebraic geometry-and also, via measure theory, is a return to his beginning in the foundations of probability.

Raja was my ardent friend and mentor, and he is sorely missed.

\section{Credits}

Figures 1, 4, and 5 are courtesy of David Weisbart.

Figures 2 and 3 are courtesy of Veda Varadarajan.

Photo of Michael Rapoport is courtesy of Mathematisches Forschungsinstitut Oberwolfach.

Photo of Ramesh Gangolli is courtesy of Ramesh Gangolli.

Photo of Trond Digernes is courtesy of Arne Asphjell.

Figure 6 is courtesy of Rita Fioresi.

Figure 7 is courtesy of Don Blasius.

Figure 8 is courtesy of UCLA. 